\title{
Characterising bonded joints with a thick and flexible adhesive layer. Part 1: fracture testing and behaviour
}

\author{
Hasegawa ${ }^{1} \mathrm{~K}$, Crocombe $^{1 *}$ AD, Coppuck ${ }^{2}$ F, Jewel ${ }^{2}$ D and Maher ${ }^{2} \mathrm{~S}$ \\ ${ }^{1}$ Mechanical Engineering Sciences, University of Surrey, GU2 7XH, UK \\ ${ }^{2}$ Gordon Murray Design, Shalford, GU4 8EP, UK \\ * Corresponding author Tel: +44(0)1483689194, Email: a.crocombe@surrey.ac.uk
}

\begin{abstract}
Adhesively bonded structural joints have increasingly found applications in automotive primary structures, joining dissimilar lighter-weight materials. Low-modulus rubbery adhesives are attracting rising interest as an alternative to conventional rigid structural adhesives due to benefits such as the excellent impact resistance they provide. This paper is the first of two parts that investigate, both experimentally and numerically, the mechanical behaviour of a rubbery adhesive and the bonded joints to be used in a lightweight automobile structure This part 1 paper characterises the fracture behaviour of the flexible adhesive layer with thick bondlines and presents a way to reliably determine the fracture mechanics parameters under a range of loading modes. Assessment of the various fracture tests indicated that DCB and SLB should provide mode I and mixed mode fracture energies but that the conventional ENF for mode II would not be practical for such compliant adhesive layers. Instead a cracked thick adherend shear specimen was developed and used. Reliable fracture energies were obtained from these specimens and a mixed mode fracture criterion developed for application in the part 2 paper.
\end{abstract}

Keywords: Polyurethane (A), Fracture Toughness (C), steels (B), resin based composites (B), mixed mode

\section{Introduction}

Adhesive bonding has been widely used in engineered products to join individual parts into a structural component. Bonding provides a number of benefits such as an ability to join dissimilar materials and a more uniform stress distribution in the joint, and has often replaced traditional welding or mechanical fastening techniques [1]. More recently, it has been increasingly used in demanding structural applications including aircraft, automobiles, and construction. The automotive industry, in particular, is paying considerable attention to using adhesive bonding to join primary structural components [2]. This trend has been driven by the extensive use of lightweight materials such as aluminium or fibre reinforced polymers (FRP) in combination with conventional steel in a quest to improve fuel consumption. As assembling such dissimilar materials by spot welding is generally difficult or impractical, adhesive bonding provides an attractive alternative.

Low modulus rubbery adhesives with high ductility have attracted rising interest for structural bonding in the automotive industry [3]. They are based on different types of polymers, including polyurethanes, acrylics, and their blends with epoxies, typically exhibiting a modulus as low as a few MPa as well as failure strain of over $100 \%$ [4]. A major advantage in their application has been claimed to be excellent impact resistance. Their high deformability allows sufficient load transfer through the joints as well as providing energy absorption during an impact event. Their damping capability can more effectively reduce noise or vibration compared with rigid structural adhesives. Also, a more uniform stress 
distribution is expected than that for rigid adhesives, which could lead to greater fatigue resistance.

Since these flexible rubbery adhesives for structural bonding application have a rather short track record [3] limited literature on their mechanical behaviour have been found. Basic ideas about their behaviour can be obtained through the work extensively conducted in the past on traditional rubbers such as natural rubbers or the cross-linked styrene-butadiene rubber (SBR) and bonded joints using those rubbers [5].

The limited literature available has reported a wide range of mechanical responses of bonded joints with polyurethane based adhesives similar to the adhesive studied in this work. These include quasi-static, fatigue and impact loading on lap shear or peel joints at various temperatures or strain rates [3, 6-8]. However, a considerable difference in properties can be expected because different adhesives were used, and because the bond thickness in those studies was much thinner than in the current application $(3 \mathrm{~mm})$. In other studies that attempted to measure fracture energies, difficulty in applying standard test geometries has been reported, presumably due to the high deformation capability of those adhesives [9-11].

The primary objective of the current research is to investigate the application of experimental and modelling procedures used successfully for thinner more rigid adhesives to thicker and more flexible adhesive systems. This has been undertaken first by characterising fracture behaviour and determining fracture energies for three different loading modes, pure mode I, mode II, and a mixed mode. Then, the structural response of bonded joints representative of those used in the vehicle structure were tested and modelled using progressive damage modelling with cohesive zone material damage models using the fracture testing results. Part 1 of the paper focuses on the fracture testing and analysis and part 2 of the paper discusses the validity of numerical prediction. The fracture parameters used in this paper are only strictly applicable when linear elastic fracture mechanics (LEFM) prevail, ie when the non-linear response is localised to the crack tip. It is anticipated that this is unlikely to be the case with these low modulus high thickness adhesive layers. Thus it is important to include the process zone in any modelling work and this has been done in part 2 of this paper. In this work the same adhesive thickness and modelling approach has been used in the fracture mechanics specimens and structural joints. The applicability of the fracture parameters to structural joints with other thicknesses has not been included in this work but is an area that could be considered further.

\section{Mode I fracture}

\subsection{Experimental methods}

Details of the double cantilever beams tested are shown in Figure 1. The substrates were short glass fibre reinforced composite (either 6 or $12 \mathrm{~mm}$ thick) and the polyurethane adhesive had a thickness of $3 \mathrm{~mm}$. The material and thickness of the substrates were determined by performing a preliminary FE analysis to establish that the substrate would not fail before crack growth was likely to occur. Two steel blocks were bonded on the end of the substrates to receive the loading pins. A notch was introduced in the middle of the bond thickness by inserting a razor blade when curing the adhesive. The tip of the notch was located $50 \mathrm{~mm}$ from the centre of the load pins. To facilitate the detection of the crack growth, a thin layer of typewriter correction fluid was applied to the adhesive on both sides. The specimen was placed in an Instron universal testing frame using clevis fixtures and load pins. Initially, the notch was slightly extended by loading the specimen to create a sufficiently sharp pre-crack. As soon as a few millimetres of extension was observed, the specimen was unloaded. The specimen was loaded again at a constant cross-head rate of $1 \mathrm{~mm} / \mathrm{min}$ and the 
crack movement was monitored with a high resolution camera connected to a PC display until it had propagated about $60 \mathrm{~mm}$. Testing was carried out on five and two specimens with 12 and $6 \mathrm{~mm}$ thick substrates respectively.

The technique used for determining the fracture energy is the compliance based beam method (CBBM) [12]. Whilst simple beam theory assumes that the substrate is fully built-in at the crack tip, in reality, root rotation occurs due to the deformation of the adhesive layer as well as significant softening of the adhesive caused by a damage process around the crack tip. Both give rise to enhanced compliance making the joints behave as if the crack is further advanced than it actually is. CBBM aims to adjust the observed crack length $(a)$ to the effective crack length, $a_{e}(=a+\Delta)$. The correction $(\Delta)$ is determined by solving the equation for compliance based on the beam theory expressed as

$$
C=\frac{8 a_{e}^{3}}{E B h^{3}}+\frac{12 a_{e}}{5 B h G}
$$

where $E, B, h$, and $G$ denote the Young's modulus, the width, the thickness, and the shear modulus of the substrate, respectively. The second term accounts for shear deformation but was ignored in the present work as it has a negligible effect compared with the first term for the geometry considered here. $G_{I C}$ can then be determined from

$$
G_{I C}=\frac{12 P^{2} a_{e}^{2}}{E B^{2} h^{3}}
$$

where $P$ is the load corresponding to the effective crack length. A flexural modulus value of $11.4 \mathrm{GPa}$ measured by a 3-point bending of the substrate was used to provide the substrate Young's modulus $E$.

\subsection{Results and discussion}

Initial testing was undertaken on the $12 \mathrm{~mm}$ substrate DCBs. During the initial loading that produced the small extension (1-2 mm) of the notch, remarkable non-linearity in the loaddisplacement curve was observed, resulting in a large increase in the compliance. This is shown in Figure 2 for a typical specimen. No visible damage in the substrates or the adhesive was observed. The effective pre-crack length calculated by the CBBM from the compliance from the linear portion of the loading curve is $79 \mathrm{~mm}$. Subtracting the pre-crack length of 50 $\mathrm{mm}$ from the effective crack length gives the correction $\Delta$, associated with the root rotation of the substrate, of $29 \mathrm{~mm}$. This is in good agreement with a crack correction value of $28 \mathrm{~mm}$ derived from a closed form equation found elsewhere [9]

$$
\Delta=h(1 / 6)^{1 / 4}\left(1+\frac{h_{a}}{h} \frac{E}{E_{a}}\right)^{1 / 4}
$$

where the subscript, $a$, denotes the adhesive. Likewise, $\Delta$ determined for the unloading curve was $41 \mathrm{~mm}$. This increase in effective crack length $(12 \mathrm{~mm})$ is likely to be due to the damage process zone developed in the adhesive near the crack tip. Indeed, a large crack tip opening displacement of about $1.5 \mathrm{~mm}$ was observed immediately before the unloading, implying a significant softening of the crack tip region could have occurred.

A representative load-displacement curve along with the measured crack length for the subsequent loading is shown in Figure 3. For all specimens, the load increased almost linearly before the onset of crack growth unlike the case of pre-cracking, this is presumably because a sufficient damage process zone has already developed ahead of the crack tip. The crack grew close to the interface, stably, but in a complicated manner, except one specimen where unstable crack growth was observed. New cracks occasionally initiated at 5 to $10 \mathrm{~mm}$ 
ahead of the main crack, but often not across the entire width, causing precise measurement of crack length to be difficult. When the new cracks initiated near the opposite interface, the main crack changed its location by jumping from one interface towards the other as shown in Figure 4. As a result, significant crack bridging by the adhesive was observed, which probably contributed to occasional load retention with crack growth as can be seen in Figure 3. It is known that when the deformation of incompressible materials such as rubbers is constrained, hydrostatic stresses develop and damage initiation tends to occur via void nucleation [5]. This might have been the case in the new crack formation close to the interface where the lateral deformation of the adhesive was highly constrained by the substrates. Since the adhesive very close to the crack tip is softened due to damage, the hydrostatic stress is assumed to peak away from the crack tip. If the stress is of the same level as a critical stress for a void nucleation, it could account for this unusual crack growth behaviour, and if so, the fracture energies might be more representative of crack initiation rather than that crack propagation. The failure mode was visually identified after the test. The locus of failure was mainly in the adhesive close to either interface, and partly in the glass fibre at the surface of substrates. Interfacial failure was rarely observed.

DCB tests using joints with a substrate thickness of $6 \mathrm{~mm}$ were conducted to assess the effect of a smaller effective crack length (more localised stresses) on the crack growth behaviour. The crack correction, $\Delta$, calculated by the CBBM approach for the initial loading and unloading was $14 \mathrm{~mm}$ and $19 \mathrm{~mm}$, respectively. Again, the former shows reasonable agreement with the value of $17 \mathrm{~mm}$ derived by the closed form equation. A smaller difference of $5 \mathrm{~mm}$ between the unloading and loading effective crack length is shown compared to 12 $\mathrm{mm}$ for the thicker substrate specimen, which is an indication of a reduced damage process zone with the more deformable substrates limiting the highly stressed region ahead of the crack tip. Indeed, the crack propagated in the adhesive without any new crack formation ahead of the main crack or crack bridging. Thus the load-displacement and crack growth curves are smoother, as shown in Figure 5. The failure mode for the two specimens tested was visually determined to be almost perfectly cohesive, with the crack paths running close to one of the interfaces.

Mode I fracture energy $\left(G_{I C}\right)$ values versus the apparent crack length obtained using the CBBM reduction method for the specimens with $12 \mathrm{~mm}$-thick and $6 \mathrm{~mm}$-thick substrates are presented in Figure 6. As noted above, the complex failure mode including crack bridging, and the resulting difficultly in monitoring crack length for the specimens with thicker substrates, inevitably contributed to the variation in the inter- and even intra- specimen values. An attempt has been made to relate the $G_{I C}$ values for each specimen with the locus of failure. The resultant schematic diagram which estimates the fracture energies depending on the failure mode is shown in Figure 7. The higher range of fracture energies, 5 to $6 \mathrm{~kJ} / \mathrm{m}^{2}$ correspond well to cohesive failure within the adhesive. Also, the $G_{I C}$ values in the lowest band of approximately $3 \mathrm{~kJ} / \mathrm{m}^{2}$ are predominantly associated with failure in the substrate. The intermediate zone of 4 to $5 \mathrm{~kJ} / \mathrm{m}^{2}$ tends to correspond to a mixed failure in the adhesive and in the surface glass fibres of the substrate, with the value decreasing as the proportion of the latter increases. In addition, the $G_{I C}$ at which the new crack formation was observed typically shows lower values of around $4 \mathrm{~kJ} / \mathrm{m}^{2}$.

\section{Mode II fracture}

\subsection{Experimental methods}

The commonly used end notch flexure (ENF) test configuration was initially considered. However, it was decided not to use this because preliminary FE analysis results indicated that premature yielding or failure would occur in the composite or steel substrate materials available. It appeared that the extremely large compliance of the thick flexible adhesive layer 
as well as a high mode II fracture energy of the adhesive made it difficult to generate sufficient shear deformation to propagate the crack without excessive specimen bending leading to substrate failure. Instead, a specimen geometry based on a Thick Adherend Shear Test (TAST) specimen, but with an artificial crack, was prepared as outlined in Figure 8. Although this is not pure mode II loading the combination of the low modulus adhesive, the high modulus and thick steel substrate result in minimal peel stresses at the overlap ends and a loading that is dominantly mode II. The geometry, hereinafter called the cracked TAST specimen contained an artificial crack of $5 \mathrm{~mm}$ in the middle of the bond layer at one end of the overlap. The pre-crack was fabricated by inserting a $3 \mu \mathrm{m}$ thick aluminium foil coated with a mould release agent into the uncured adhesive. No preliminary crack extension was undertaken in this particular testing because the $3 \mu \mathrm{m}$ thick pre-crack was considered to be sharp enough. Testing was conducted at a cross head speed of $1 \mathrm{~mm} / \mathrm{min}$ using an Instron servo-mechanical testing frame. The crack growth was periodically recorded using a digital microscope so that it could later be correlated with the load and displacement. The specimen was held in the test machine using mechanical wedge action grips. Testing was carried out on three specimens.

The mode II fracture energy $\left(G_{I I C}\right)$ of the adhesive was determined by computing the Jintegral at the peak load using the FE code ABAQUS. The J-integral is effectively the same as the strain energy release rate for linear elastic fracture mechanics. Thus the J-integral value for the mode II load at the onset of crack growth can be regarded as the critical strain energy release rate or fracture energy $\left(G_{I I C}\right)$. An alternative approach could have developed an analytical solution based on the work of Williams [13] with cracked laminates. The use of FEA enabled the effect of different crack positions to be examined. The elements used for the steel substrates were 8-node quadrilateral plane stress elements with reduced integration (CPS8R). For the adhesive, 8-node quadrilateral plane strain elements with reduced integration (CPE8R) were used. The FE model geometry is shown in Figure 9. The crack was defined as a "seam" in ABAQUS, located $0.2 \mathrm{~mm}$ away from the upper interface. The crack was placed near the interface because in the experiments the pre-crack propagated in the direction normal to mode I, towards the upper interface, and then grew close to the interface in mode II. The initial crack length was set as $7 \mathrm{~mm}$, matching the experimentally measured crack length at the peak load. "Quarter point" elements were used to produce the appropriate crack tip singularity. The material properties used for the adhesive were a shear modulus of $2.8 \mathrm{MPa}$ and Poisson's ration of 0.45 , whilst a modulus of $200 \mathrm{GPa}$ and Poisson's ratio of 0.33 were used for the steel substrate. The value of the adhesive shear modulus was obtained from thick adherend shear tests. One end of the steel substrate was fully constrained and the load was applied at the other end as a pressure.

\subsection{Results and discussion}

A typical experimental load-displacement curve of the cracked TAST specimen is shown in Figure 10. For all specimens, the load increased almost linearly, during which the pre-crack tip was observed to gradually open up. The crack propagated rapidly when the load reached its peak, resulting in failure with the sharp drop of the load. The locus of failure was visually identified to be predominantly within the adhesive, close to interface. It is important to note that the crack propagation direction was found to be towards the interface as can be seen in the appearance of the failed specimen shown in Figure 11. This type of crack growth has been commonly found in adhesive joints under a shear-dominant loading mode [14]. The propagation direction is often normal to the angle of the maximum mode I strain energy release rate because the mode I fracture energy of an adhesive is generally much lower than 
that for mode II. Once the crack approached the interface it was constrained to grow in mode II.

J-integral values, corresponding to the peak load of $2.35 \mathrm{kN}$ for the cracked TAST specimen, were found to be $11.6 \mathrm{~kJ} / \mathrm{m}^{2}$. J-integral values for various loads up to the peak load are fitted well using a quadratic function of the load as they theoretically should. As mentioned above, the crack initially moved in a direction that was not pure mode II, but more likely to be in a direction normal to the angle maximising mode I strain energy release rate $\left(G_{I}\right)$. Assuming the adhesive experienced pure shear loading, the angle of maximum $G_{I}$ is located $45^{\circ}$ from the direction parallel to the initial crack. The J-integral values for this direction was also calculated from another FE model where a pre-crack was located in the middle of bondline. The value of the load corresponding to this initial crack opening is around $1900 \mathrm{~N}$, and gave a J-Integral value of $5.1 \mathrm{~kJ} / \mathrm{m}^{2}$. This appears to be in good agreement with the $G_{I C}$ values determined by the mode I fracture testing.

\section{Mixed mode fracture}

\subsection{Experimental methods}

A single leg bending (SLB) specimen geometry, see Figure 12, was adopted due to the availability of the testing rig and the ease of specimen manufacture. As with the DCB specimens, preliminary FE modelling was undertaken to determine a SLB geometry where fracture would precede substrate failure. This resulted in substrates made of the same composite laminates as the DCB but being thicker in order to avoid premature failure. The dimensions of the substrate were $15 \mathrm{~mm}$ thick, $25 \mathrm{~mm}$ wide, and $550 \mathrm{~mm}$ long. The substrates were bonded to form the SLB joint using a $3 \mathrm{~mm}$ layer of the target adhesive. An initial notch was fabricated in the same way as in the DCB (razor blade), with its tip located $130 \mathrm{~mm}$ from the nearest support rollers, see Figure 13. Before loading, the notch was extended by a few millimetres by applying pressure to the razor blade so ensuring a sharp crack tip. In order to keep the specimen horizontal (in the unloaded state), a spacer made from the same substrate material was bonded to the lower surface of the upper specimen using a structural epoxy adhesive, see Figure 13. The specimen was placed on a 3-point bending rig fixed in an Instron universal testing frame. The loading cylinder was positioned at the centre of the 500 $\mathrm{mm}$ span, between the two supporting rollers. With the initial notch to the half span length ratio of 0.52 , stable crack growth was expected to occur according to a closed form analysis conducted by Fernlund and Spelt [15]. At the cracked end of the specimen only the upper substrate was supported, allowing the lower substrate to be free to move (this is the basis of the SLB test). Both the supporting rollers and load cylinders were free to rotate. The specimen was loaded at a constant cross-head rate of $1 \mathrm{~mm} / \mathrm{min}$ during which crack growth up to about $60 \mathrm{~mm}$ was monitored using the same method as in the DCB testing. Testing was conducted on three specimens.

Reduction of the test data to provide the mixed mode fracture energy $\left(G_{I / I I C}\right)$, and the mode I $\left(G_{I}\right)$ and mode II $\left(G_{I I}\right)$ components was carried out following the CBBM technique as used in the mode I fracture testing. The effective crack length, $a_{e}$, introduced in the section for mode I fracture is determined from the measured compliance data using a closed form equation based on beam theory [16] expressed as

$$
C=\frac{7 a_{e}^{3}+2 L^{3}}{8 B h^{3} E}
$$


where $L$ is the half span between the supporting points. The CBBM technique determines $G_{C}$ using the equation

$$
G_{C}=\frac{21 P^{2} a_{e}^{2}}{16 B h^{3} E}
$$

where $P$ is the load, $E, B, h$ are the Young's modulus, the width and the thickness of one substrate, respectively. As symmetric substrates were used, the components for individual modes were obtained by partitioning $G_{C}$ according to $G_{I}: G_{I I}=4: 3$ [17].

\subsection{Results and discussion}

Typical load-displacement and crack length-displacement relationships are shown in Figure 14. All specimens showed an almost linear load-displacement response before the onset of crack growth, then a more gradual load increase to a broad peak, followed by considerable load retention in spite of continued crack extension. After opening, the crack was driven towards the upper interface and propagated stably close to the interface as can be seen in Figure 15. The crack deflection towards the interface is considered to be associated with the tendency for the crack to propagate in the direction of the maximum mode I strain energy release rate as was seen in the mode II fracture testing. As in the DCB testing, new cracks sometimes initiated ahead of the propagating crack tip. However, unlike the DCB testing significant crack bridging was not observed because the new cracks always formed on the same interface as the main crack growth. The failure mode was visually evaluated after the tests and confirmed to be mainly cohesive.

Figure 16 shows the total fracture energy values, $G_{I / I I C}$, with regard to the observed crack length for the three specimens determined using the CBBM methods, along with the mode I and mode II components obtained by partitioning $G_{I / I I C}$. It can be seen that the $G_{C}$ values monotonically increase with the crack length, tending towards a plateau. In the figure, the values from one specimen (SLB-1) are obviously larger than those for the others, by about $2000 \mathrm{~J} / \mathrm{m}^{2}$ for $G_{I / I I C}$ and $1000 \mathrm{~J} / \mathrm{m}^{2}$ for $G_{I}$ and $G_{I I}$. A subtle difference in the failure surfaces among the three specimens was observed, where the crack propagated closer to the interface for the specimens with the lower $G_{I / I I}$ values, however, this does not seem to be sufficient to account for the significant difference in the fracture energies.

It should be noted that there is an uncertainty in the application of the data reduction method. The effective crack length, $a_{e}$, calculated by the CBBM approach from the initial compliance before crack growth is about $220 \mathrm{~mm}$, and approximately $90 \mathrm{~mm}$ larger than the measured crack length throughout the crack growth. This is presumably attributable to the extremely compliant adhesive layer. This value is already close to the half span length of $250 \mathrm{~mm}$ and would mean that significant compression effects may be induced by the loading cylinder on the equivalent crack tip after only a short amount of crack propagation. This might account for the increase in $G c$ with crack length from the CBBM method. Thus, although it might be controversial, it seems to be reasonable to take the fracture energy values corresponding to the smaller measured crack lengths (up to $10 \mathrm{~mm}$ ) from the CBBM approach.

\section{Fracture Energy Envelope}

The mode I and mode II components of the mixed mode fracture energy for the different specimens are plotted on a fracture energy envelop shown in Figure 17 together with the $G_{I C}$ values averaged over the entire crack length for the mode I and the $G_{I I C}$ value obtained from the $\mathbf{J}$ integral for the mode II tests. It can be seen that the mixed mode fracture energies are distributed above the line representing the widely used fracture criteria relationship expressed 
in Eqn (6). The data can be better expressed by the power law criteria with exponents of 1.5 as shown in the figure. Thus, the latter was applied to the progressive damage modelling of representative joints described in the part 2 paper. Future work could be directed to further populating this fracture energy envelope, see e.g. [18] for other possible tests. Further, it should be noted that conditions for linear elastic fracture mechanics may not be fully applicable with these low modulus, high thickness adhesive layers and thus the applicability of the fracture energy envelope also needs to be explored with different thickness adhesive layers in future work.

$$
\frac{G_{I}}{G_{I C}}+\frac{G_{I I}}{G_{I I C}}=1
$$

\section{Conclusions}

Fracture behaviour of a $3 \mathrm{~mm}$ thick flexible polyurethane adhesive layer was investigated under a range of loading modes and the fracture energies were determined. The loading modes included pure mode I, pure mode II, and a mixed mode.

The mode I fracture testing was carried out using two symmetric DCB specimen geometries with different substrate thicknesses of $12 \mathrm{~mm}$ and $6 \mathrm{~mm}$. Substrate materials having relatively low modulus and high strength such as the short fibre composites used in this paper appeared to work effectively, in that they not only prevent premature failure or yielding but also restrain the damage process zone during crack growth to be sufficiently small to allow for the use of general data reduction methods based on the beam theory. However, consistent crack growth can be hindered by a new crack formation ahead of the existing crack presumably due to relatively low cohesive strength as well as hydrostatic stress effects. Utilising $6 \mathrm{~mm}$ thick substrates with higher flexibility solved this problem by reducing the size of the highly stressed region around the crack tip, which provided reliable fracture energy values of $G_{I C}$ for this adhesive of around $5.5 \mathrm{~kJ} / \mathrm{m}^{2}$. Based on the observation of the failure surfaces a relationship between the fracture energy values and corresponding crack paths were found, with the cohesive adhesive failure having the highest fracture energies.

Instead of conventional ENF testing, which was found to be difficult to apply due to extremely high compliance of the adhesive layer, the mode II fracture testing was conducted using a specimen geometry similar to a TAST configuration, but with an artificial pre-crack. Initial crack growth was not mode II. However, based on the experimental observation of the actual crack growth, the crack length and location of the crack when mode II crack propagation occurred were estimated. Data reduction to obtain the values of $G_{I I C}$ was undertaken using quasi-static FE analysis. The FE analysis computed the J-integral corresponding to the critical load and the crack location, and determined the value of $G_{I I C}$ to be around $12 \mathrm{~kJ} / \mathrm{m}^{2}$.

The mixed mode fracture energy with a mode mixity $\left(G_{I}: G_{I I}\right)$ of $4: 3$ was measured using single leg bending (SLB) specimens. The specimen compliance in the test results suggested that, due to the high flexibility of the adhesive layer, the data reduction methods based on the beam theory are only applicable to an early stage of the crack growth. Taking this into account, the total mixed mode fracture energy was determined to be around $8 \mathrm{~kJ} / \mathrm{m}^{2}$. A mixed mode fracture criteria was considered based on the range of fracture energies that had been 
determined. It was suggested that a power law mixed mode fracture criteria with exponents of 1.5 was a good fit to the mode I, II and the mixed mode fracture energies determined.

\section{References}

[1] Kinloch, A. J. Adhesion and adhesives: science and technology. London: Chapman and Hall; 1987

[2] Pohlit, D.J., Dillard, D.A., Jacob, G.C. and Starbuck, J.M. 'Evaluating the Rate-Dependent Fracture Toughness of an Automotive Adhesive' Journal of Adhesion., 84(2): 143-163; 2008

[3] Loureiro, A. L., da Silva, L. F. M., Sato, C. and Figueiredo. M. A. V. 'Comparison of the mechanical behaviour between stiff and flexible adhesive joints for the automotive industry' Journal of Adhesion, 86: 765-787; 2010

[4] Burchardt, B. 'Advances in polyurethane structural adhesives', in: Dillard, D. A. (ed.) Advances in structural adhesive bonding. Oxford: Woodhead Pub. Ltd. p. 35-65; 2010

[5] Kinloch, A. J. and Young, R. J. Fracture behaviour of polymers. London: Elsevier Applied Science; 1983.

[6] Ashcroft, I. A., Comyn, J. and Tellwright, S. 'Adhesives for automotive windscreen replacement: Kinetics of cure and bond strength', International Journal of Adhesion Adhesives, 29(2):155-166; 2009.

[7] Banea, M., D. and da Silva, L. F. M. 'Mechanical characterisation of flexible adhesives' Journal of Adhesion, 85: 261-285; 2009.

[8] Banea, M., D. and da Silva, L. F. M. 'The effect of temperature on the mechanical properties of adhesives for the automotive industry' Proc. IMechE Part L: J. Materials: Design and Applications, 224: 51-62; 2010.

[9] Park, S. and Dillard, D. A. 'Development of a simple mixed-mode fracture test and the resulting fracture envelope for an adhesive' International Journal of Fracture, 148:261-271; 2007.

[10] Suarez, J. C., Lopez, F., Miguel, S., Pinilla, P. and Herreros, M.A. 'Determination of the mixed-mode fracture energy of elastomeric structural adhesives: evaluation of debonding buckling in fibre-metal hybrid laminates', Fatigue and Fracture of Engineering Materials and Structures, 32(2):127-140; 2009.

[11] MacLure, A., Chalivendra, V.B. and Ramotowski, T. 'Effect of Pressure Cycling on Fracture Energy of Polyurethane/Aluminum Adhesive Bonds', Journal of Adhesion, 85(12): 869-888; 2009.

[12] de Moura, MFSF, 'Progressive Damage Modelling'. In:da Silva LFM and Ochesner A (eds.), Modelling of adhesively bonded joints, Verlag: Springer, p. 155-182, 2008.

[13] Williams, J. G., 'On the calculation of energy release rates for cracked laminates' International Journal of Fracture, 36:101-119; 1988. 
[14] Dillard, D. A, Singh, H. K., Pohlit, D. J. and Starbuck, J. M. 'Observations of decreased fracture toughness for mixed mode fracture testing of adhesively bonded joints' Journal of Adhesion Science and Technology, 23:1515-1530; 2009.

[15] Fernlund, G. and Spelt, J. K.'Mixed-mode fracture characterization of adhesive joints' Composites Science and Technology, 50: 441-449; 1994.

[16] Davidson, B. D. and Sundraraman, V. 'A single leg bending test for interfacial fracture toughness determination'. International Journal of Fracture, 78:193-210; 1996.

[17] Dillard, D. A. 'Other mixed mode adhesive fracture test specimens' in: da Silva, L. F. M., Dillard, D. A., Blackman, B. R. K. and Adams, R. D. (eds.) Testing adhesive joints -best practices-. Weinheim: Wiley-VCH Veerlag \& Co. pp. 194-201; 2012.

[18] Chaves FJP, de Moura MFSF, da SilvaLFM, Dillard DA, and Esteves V, 'Fracture mechanics tests in adhesively bonded joints: a literature review', The Journal of Adhesion 90: 955-992, 2014. 


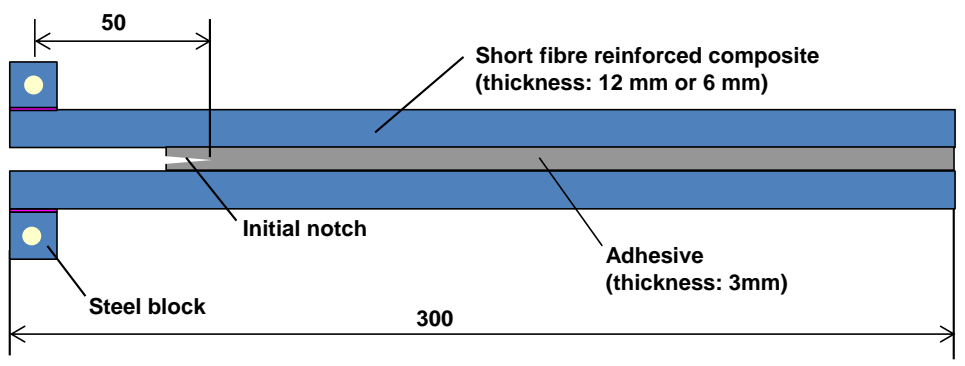

Figure 1 DCB specimen geometry.

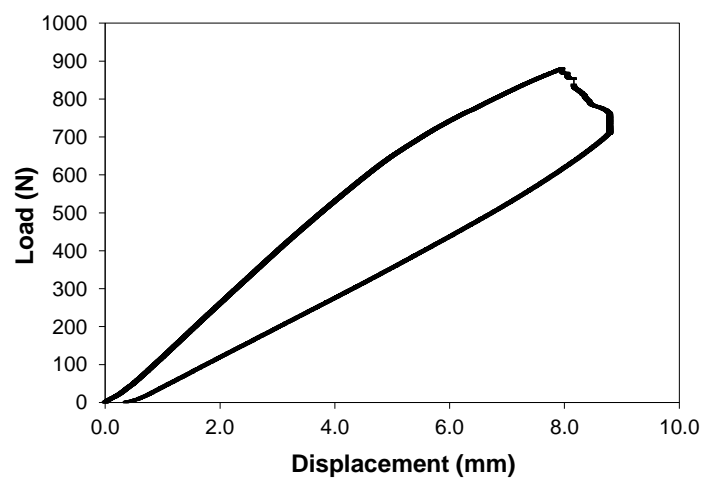

Figure 2 A representative load-displacement curve in the mode I pre-cracking.

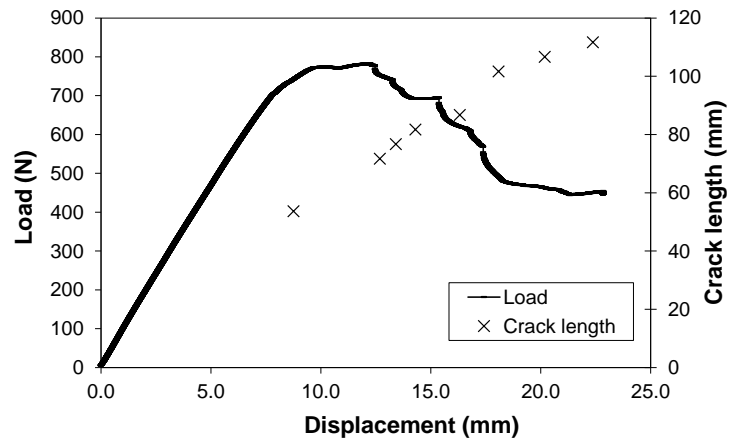

Figure 3 A representative load-displacement curve with crack length for $12 \mathrm{~mm}$-thick substrate.

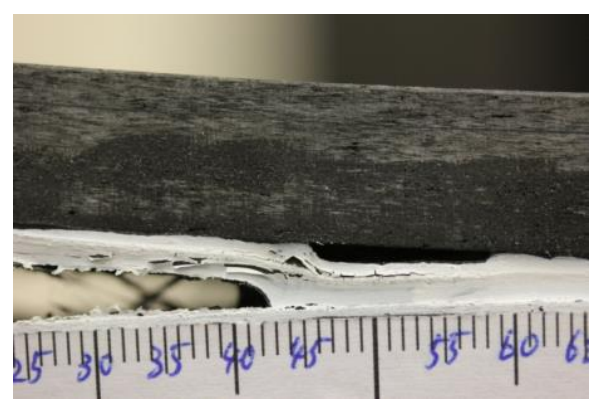

Figure 4 A crack jumping from the lower interface to the upper interface and the bridging observed for a DCB joint with substrate thickness of $12 \mathrm{~mm}$.

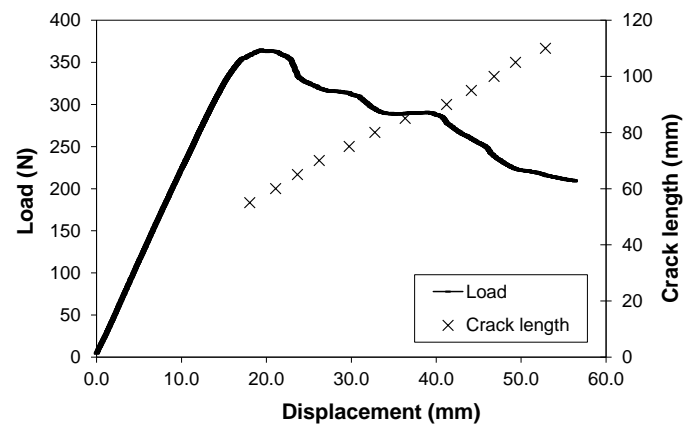


Figure 5 A representative load-displacement curve with crack length for $6 \mathrm{~mm}$-thick substrate.

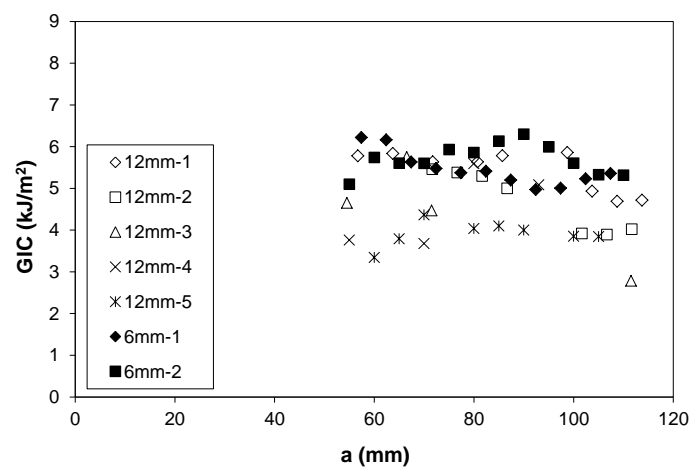

Figure $6 G_{I C}$ values for different crack lengths and specimens.

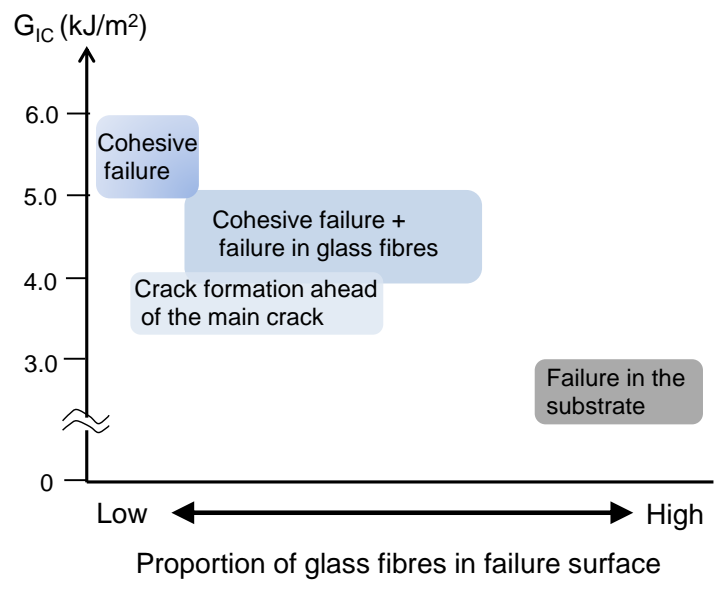

Figure 7 Schematic diagram on the relationship of the fracture energy and the failure mode.
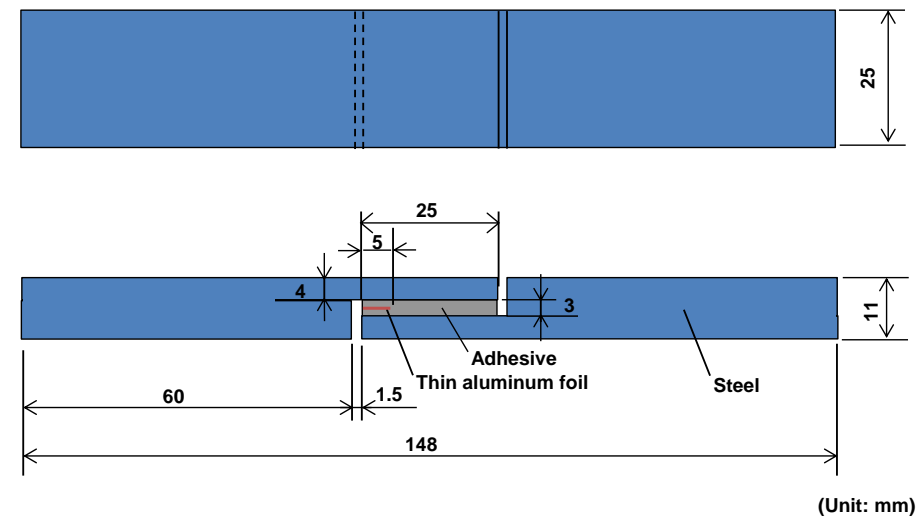

Figure 8 Outlines of the specimens for mode II fracture testing. 


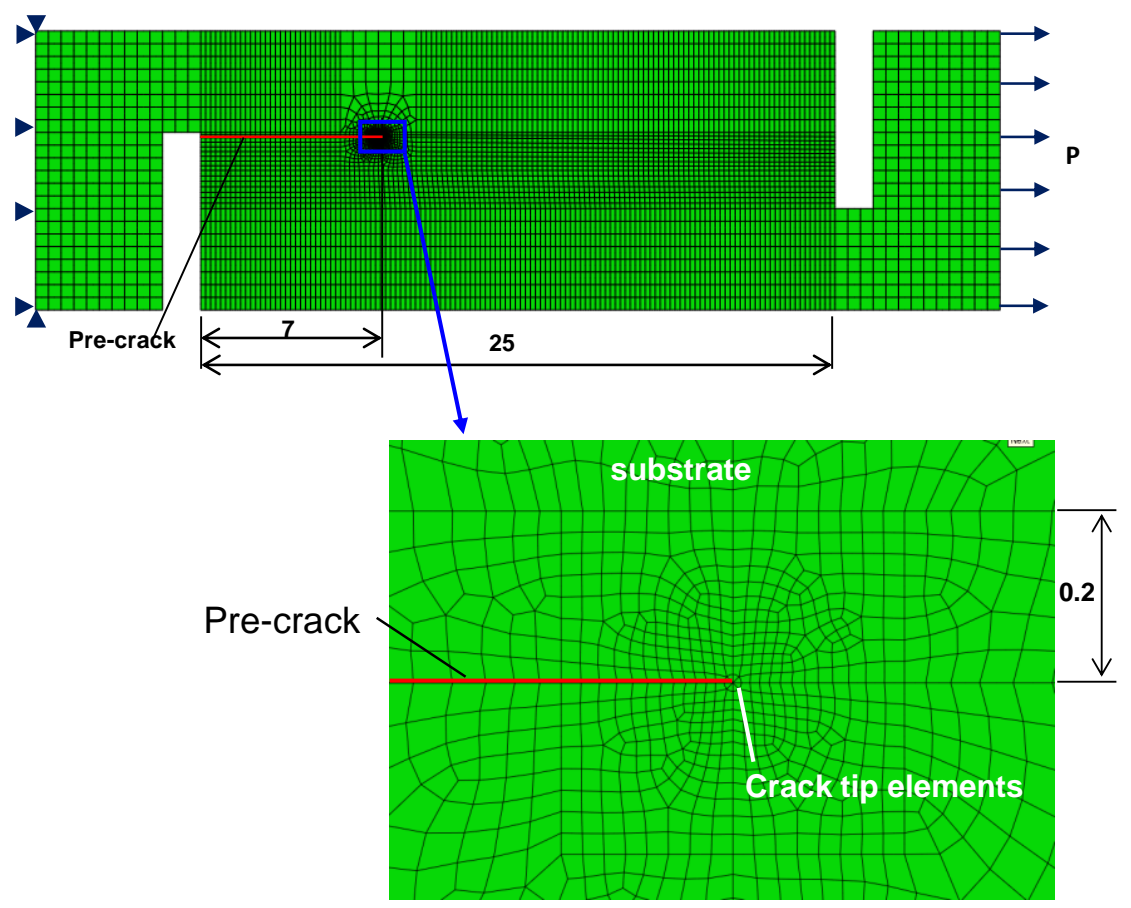

Figure 9 FE model of the cracked TAST specimen.

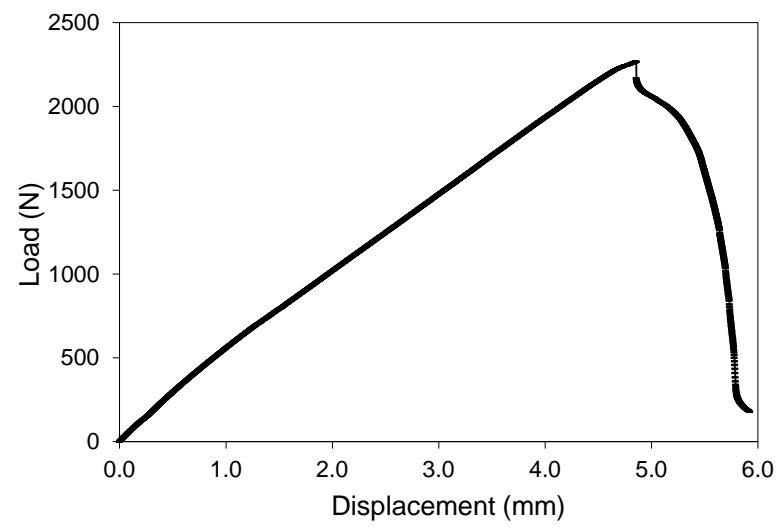

Figure 10 A typical load-displacement curve for the cracked TAST specimen.

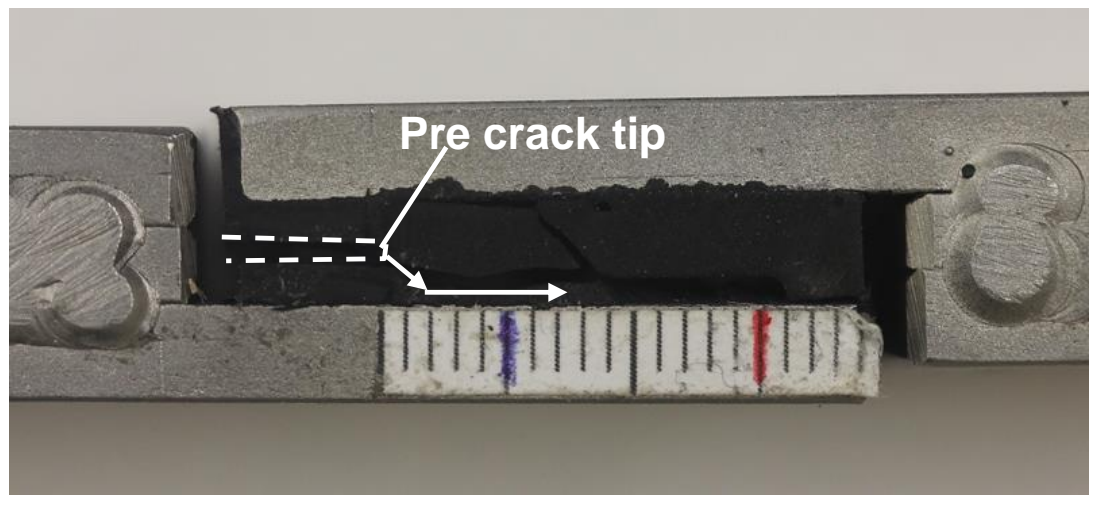

Figure 11 Appearance of a cracked TAST specimen after testing. 


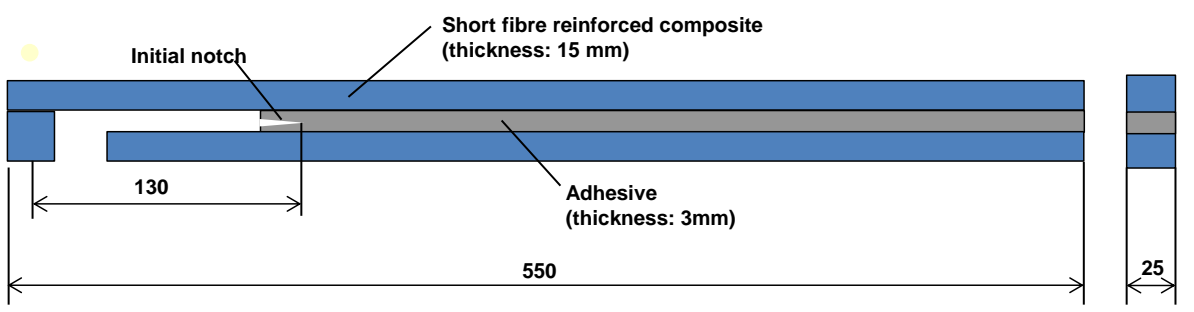

(Unit: mm)

Figure 12 Outline of the SLB specimen.

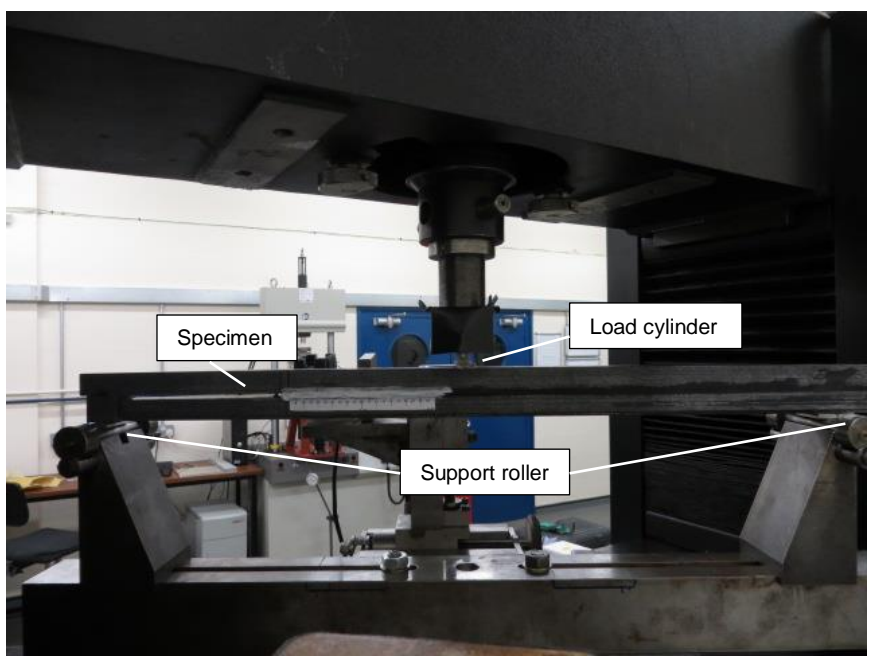

Figure 13 A test set-up for the SLB testing.

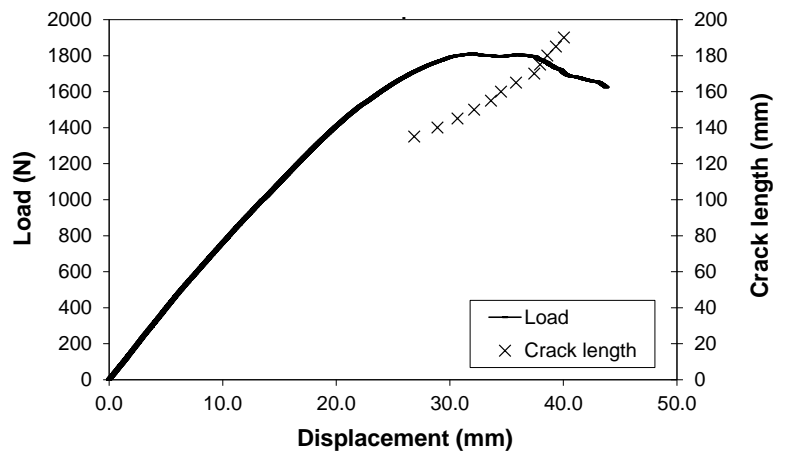

Figure 14 A typical load-displacement and load-crack length curve for the SLB specimen. 


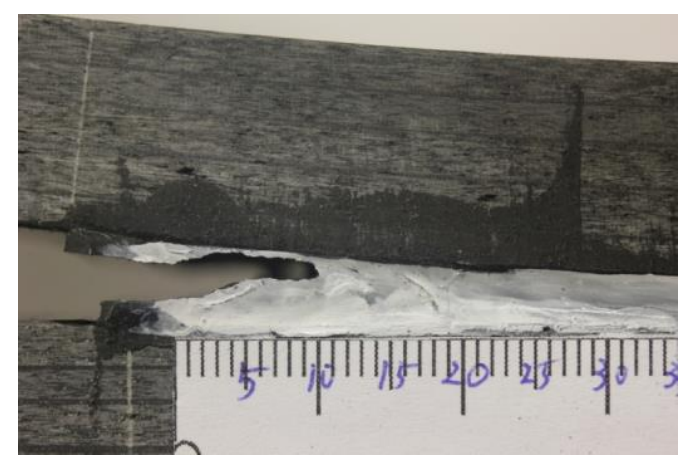

Figure 15 Crack propagation close to the upper interface in the SLB testing.

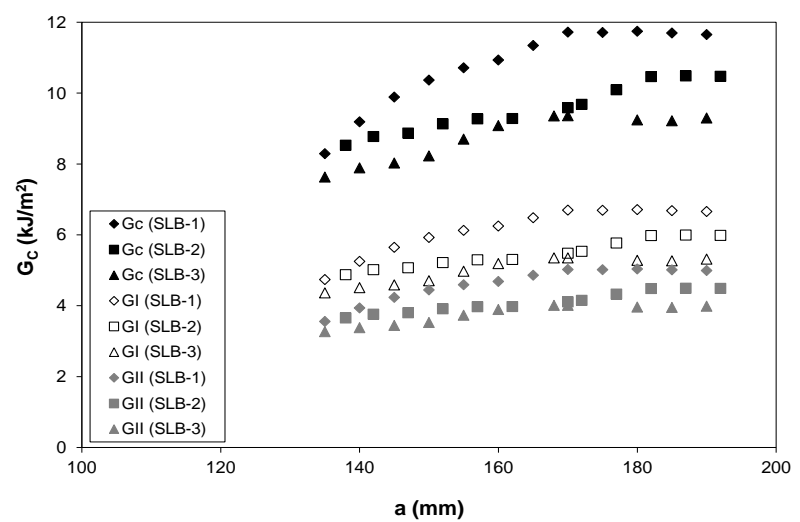

Figure $16 G_{C}$ values and the mode I and mode II components $\left(G_{I}\right.$ and $\left.G_{I I}\right)$ for different crack lengths and specimens.

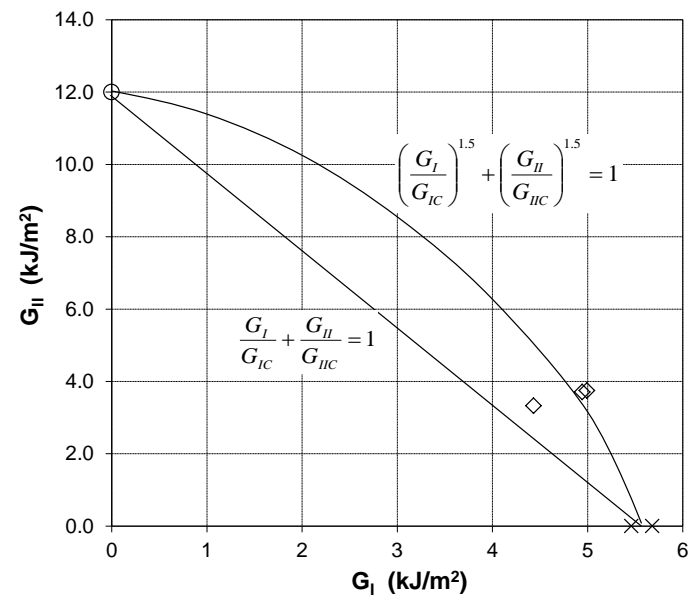

Figure 17 Fracture envelop based on the three loading modes. 
